\title{
La ejecución de los laudos internacionales en Ecuador y el Código Orgánico General de Procesos
}

\author{
Vanesa Aguirre Guzmán*
}

\begin{abstract}
SUMARIO: 1. ¿Son términos sinónimos "reconocimiento" y "ejecución" de decisiones extranjeras? 2. Naturaleza jurídica del laudo arbitral que se somete al procedimiento de homologación y ejecución. 3. El reconocimiento y ejecución de laudos arbitrales internacionales en las convenciones de Nueva York de 1958 y Panamá de 1975. 4. El Código Orgánico General de Procesos y las normas sobre homologación y ejecución de sentencias, laudos arbitrales y actas de mediación expedidos en el extranjero. 5. Conclusiones.
\end{abstract}

\section{1. ¿Son términos sinónimos "reconocimiento" y "ejecución” de reso- luciones extranjeras?}

Cualquier análisis sobre el régimen aplicable al reconocimiento y ejecución de resoluciones que no se han dictado en el territorio del país donde se pretende tengan vigor, debe partir de una constatación: aquellas no gozan inicialmente de la misma eficacia que las proferidas por los tribunales nacionales. Pero es necesario encontrar un punto medio entre los extremos que representarían, por un lado, negar absolutamente la calidad de título de ejecución a la resolución extranjera, y por otro, otorgar vía libre a su ejecución. En suma, se trata de exigir un cierto control de la decisión extranjera, sea judicial o arbitral, lo cual parece razonable y es admitido casi unánimemente en el derecho comparado ${ }^{1}$.

\footnotetext{
* Licenciada en Ciencias Jurídicas y Abogada por la Pontificia Universidad Católica del Ecuador. Especialista Superior en Derecho Procesal y en Docencia Universitaria por la Universidad Andina Simón Bolívar, Sede Ecuador (UASB-Ecuador). Diploma de Estudios Avanzados y Doctora por la Universidad Pablo de Olavide, Sevilla (Departamento de Derecho Público). Docente del Área de Derecho de la UASB-Ecuador. Secretaria del Instituto Ecuatoriano de Derecho Procesal. Árbitro del Centro de Arbitraje y Mediación de la Cámara de Comercio de Quito. Abogada en libre ejercicio.

1. Cfr. S. ANDRAde Ubidia, "En torno al tema del reconocimiento y ejecución de sentencias extranjeras y laudos internacionales". En: Foro, Revista de Derecho, No. 6 (II semestre, 2006), pp. 61-62. (disponible en $<$ http://repositorio.uasb.edu.ec/bitstream/10644/1506/1/RF-06-TC-Andrade.pdf >, acceso: 12 de julio de 2015). Vid también J. Montero Aroca y J. Flors Matíes. Tratado de proceso de ejecución civil, t. I, Valencia: Tirant lo Blanch, 2004, p. 149.
} 
Una evidencia tan patente nos ayuda a sostener que aquel "término medio" es un proceso de homologación o reconocimiento - también conocido como exequátur-, el cual encuentra su fundamento en la necesidad de que los países cooperen entre sí para que la tutela efectiva pueda realizarse fuera de las fronteras del país en que se expidió la resolución respectiva ${ }^{2}$. El aumento del tránsito entre países de personas así como el intercambio de bienes y servicios es cada vez mayor y, lógicamente, aumentan los conflictos de relevancia jurídica; por ello, no atender a la tutela transfronteriza equivaldría hoy en día a negar esta realidad ${ }^{3}$.

¿Qué implica este reconocimiento? No se trata de otorgar "validez" a la sentencia o al laudo arbitral, pues gozan de ella plenamente. El exequatur implica un proceso de asimilación de la resolución que es producto de un sistema normativo ajeno al del país receptor, por lo cual las disposiciones nacionales y las de derecho internacional tienen por finalidad regular los posibles conflictos que puedan surgir de esa equiparación ${ }^{4}$. Se trata, pues, de verificar requisitos mínimos de regularidad cuya finalidad central es velar porque en el proceso respectivo se haya cumplido al menos con las reglas del debido proceso y que no pendan sobre ella recursos, a menos de que un instrumento internacional contemple la posibilidad de la ejecución sin ningún paso previo. Una vez que la resolución internacional se ha asimilado, adquiere carta de título de ejecución y procede entonces su ejecución.

2. V. Moreno Catena, La ejecución forzosa, p. 83; vid., igualmente, J. Montero Aroca y J. Flors MATíEs, Tratado de proceso de ejecución civil, t. I, p. 149.

3. En este aspecto, bien recuerda el Proyecto de código modelo de cooperación interjurisdiccional para Iberoamérica en su Exposición de motivos que "La tutela judicial transnacional es una exigencia de los tiempos actuales, ya que constantemente las relaciones jurídicas, sobre diversos aspectos, traspasan las fronteras de un Estado. Asegurar la efectividad de una tutela judicial sin fronteras significa mucho más que solamente reconocer las decisiones judiciales extranjeras ejecutoriadas pronunciadas en procesos de conocimiento. Todo lo que sea necesario para asegurar la efectividad de la jurisdicción debe estar comprendido en la idea de una tutela judicial transnacional, como son las medidas de urgencia, los actos de ejecución, los actos destinados a la comunicación procesal o incluso los actos probatorios. Poco importa si se trata de Derecho Público o Derecho Privado; de la misma manera, la jurisdicción ha de ser efectiva y estar pautada en los mismos principios e ideas de la justicia transnacional". (Instituto Iberoamericano De Derecho Procesal, Proyecto de Código modelo de cooperación interjurisdiccional para Iberoamérica. En: Revista Internauta de Práctica Jurídica, Núm. 2, año 2008, pp. 89-116 (disponible en <http://www.uv.es/ajv/art_jcos/art_jcos/ num22/conclusiones/C\%C3\%B3digo\%20Modelo\%20de\%20Cooperaci\%C3\%B3n.pdf $>$; acceso: 7 de julio de 2015).

4. Vid. S. ANDRADE Ubidia, "En torno al tema del reconocimiento y ejecución de sentencias extranjeras y laudos internacionales", p. 62. 
De ahí que el exequatur sea aplicable esencialmente a las decisiones en las cuales el pronunciamiento es de condena, pues en los casos de la sentencia sentencia desestimatoria - en la que existe una realidad acomodada al deber ser de la sentencia- o en el de la sentencia que estima pretensiones declarativas, la resolución encuentra con la declaración del derecho su propia fuerza, al hacer cesar, con esa declaración, un estado de incertidum$b^{2}{ }^{5}$. En el supuesto de la sentencia constitutiva, por tener precisamente ese efecto una vez que alcanza la calidad de cosa juzgada, no se requiere de actividad ejecutiva; aunque es una figura autónoma, participa de los caracteres de las sentencias de mera declaración y de condena: el ius dicere lleva implícito un cambio en el estado actual de las cosas, y al mismo tiempo, con la declaración, cesa la incertidumbre del derecho ${ }^{6}$.

Por estas razones, GoLDSCHMIDT recuerda que "no hay ejecución sin reconocimiento, pero sí puede haber reconocimiento sin ejecución"7; desde luego, si se pretende la inscripción de la resolución extranjera, sería forzoso homologarla a efectos de que no quede ninguna duda sobre su validez.

No parece entonces razonable sostener de primera mano que una sentencia o laudo extranjeros pueden acceder a la ejecución, sin más, en el país donde se pretende tengan eficacia. Esto no quiere decir que el exequatur sea un óbice para la vigencia plena de estas resoluciones, sino que -insistimos - es el mecanismo procesal idóneo para verificar requisitos mínimos de regularidad de la resolución a efectos de que se reconozca como consecuencia lógica su efecto de cosa juzgada y pueda incoarse entonces su ejecución.

Como se verá enseguida, tampoco hay una razón de fondo para sostener que un laudo internacional no deba sujetarse al proceso de homologación. También advertiremos que, generalmente, varios instrumentos internacionales hablan del "reconocimiento" y "ejecución" del laudo, y no únicamente de "ejecución" de la resolución, aunque en algunas regiones se ha reconocido la necesidad de eliminar este paso intermedio en aras a lograr una tutela más expedita a favor del interesado.

5. Como bien enseña J. Montero ArocA, Trabajos de derecho procesal. Barcelona: Bosch, 2001, p. 27; en el mismo sentido, vid. M. A. FERNÁNDEZ-BALLESTEROS, La ejecución forzosa y las medidas cautelares en la nueva Ley de Enjuiciamiento Civil, Madrid: Iurgium Editores, 2001, pp. 31-35.

6. G. Chiovenda, Principios de derecho procesal civil, t. I (trad. de la $3^{\text {a }}$ edición italiana y prólogo por J. CASAIS y SANTAló), Madrid: Reus, 2000, pp. 236-437.

7. En S. ANDRAde Ubidia, "En torno al tema del reconocimiento y ejecución de sentencias extranjeras y laudos internacionales", p. 62. 
Así, el exequátur viene a ser un procedimiento de carácter netamente constitutivo-procesal; por ello, su objeto es distinto del que fue materia de la decisión extranjera ${ }^{8}$ y tal característica, por mucho que pueda perderse de vista al simplificar el razonamiento hasta el punto de negar que no debe pasarse por la homologación, impide que puedan revisarse aspectos de fondo de la sentencia o laudo. Y esto es lo que debería tenerse presente siempre para evitar considerar al exequátur como un trámite inútil, complicado o como un impedimento para la ejecución de los laudos.

No obstante, no han faltado opiniones que han sostenido 9 - debido, quizá, a la defectuosa regulación del tema en el Código de Procedimiento Civil (CPC) - , que es posible incoar la ejecución de una resolución judicial o arbitral extranjera sin necesidad de tramitar el proceso de homologación. Como se analiza más adelante, la regulación del COGP parecería en principio más adecuada, sobre todo, porque incluye por fin a los laudos internacionales (ya veremos que respecto de los laudos dictados contra el Estado se consigna una excepción), pero era necesario mencionar el antecedente para apartar la idea de que la resolución extranjera goza siempre de la calidad de "título ejecutivo", y, por tanto, susceptible de llevarse a ejecución sin más. Incluso forzando a ese extremo el razonamiento llega a ser inconveniente, porque no han faltado casos en los cuales algunos tribunales ecuatorianos consideraron necesario analizar la "ejecutividad" de la obligación contenida en el "título ejecutivo extranjero", y efectuaron al final un verdadero examen sobre el fondo del asunto ${ }^{10}$, con lo cual, paradójicamente, se terminó desvirtuando la eficacia de la decisión.

Por otra parte, se advierte que el CPC, en efecto, no establece la vía a seguir para el reconocimiento y ejecución de una sentencia extranjera como lo hace el COGP; mientras éste no entre en vigencia (22 de mayo de 2016), tal como sucede al momento en que se escriben estas líneas, es necesario explicar cuál es el régimen procesal aplicable, incluso para contrastarlo con la nueva regulación y poder confirmar si ésta resulta o no más conveniente.

8. F. Cordón Moreno, El proceso de ejecución. Elcano: Aranzadi, 2002, p. 75.

9. Por ejemplo, vid. A. Guerra BAstidas y F. AlbÁn Escobar, Realidad procesal de la ejecución de la sentencia. Quito: s/e, 1999, pp. 253-255.

10. Vid., la sentencia de la Corte Suprema de Justicia de 19 de septiembre de 1975, publicada en la Gaceta Judicial Serie XII, No. 10, pp. 2052-2054. En el CPC no se distingue entre "título ejecutivo" y "título de ejecución". La diferencia entre estas dos categorías radica esencialmente en que mientras el título ejecutivo requiere de la sustanciación de un juicio ejecutivo, el título de ejecución accede directamente a la fase de ejecución. 
Como se anotó, en Ecuador se ha discutido mucho si la vía ejecutiva constituye o no la pertinente para tramitar el reconocimiento/ejecución de una resolución extranjera, en consideración a que el artículo 414 CPC está ubicado, precisamente, en el parágrafo dedicado al juicio ejecutivo. Esta disposición dice:

Las sentencias extranjeras se ejecutarán si no contravinieren al Derecho Público Ecuatoriano o a cualquier ley nacional y si estuvieren arregladas a los tratados y convenios internacionales vigentes.

A falta de tratados y convenios internacionales, se cumplirán si, además de no contravenir al Derecho Público o a las leyes ecuatorianas, constare del exhorto respectivo:

a) Que la sentencia pasó en autoridad de cosa juzgada, conforme a las leyes del país en que hubiere sido expedida; $y$,

b) Que la sentencia recayó sobre acción personal.

El principio que fija la norma es que si existe tratado o convenio internacional, se estará a lo que disponga dicho ordenamiento (Ecuador es signatario de varias convenciones internacionales sobre la materia) ${ }^{11}$. Este aspecto - tan obvio- no representa mayor inconveniente. Pero a falta de tratado o convenio, el artículo 414 del CPC refiere, como se desprende de la lectura del inciso segundo, a la necesidad de que el tribunal ecuatoriano verifique ciertos requisitos de regularidad de la sentencia extranjera.

Si se advierte bien, el artículo 414 del CPC no señala que el trámite aplicable sea el del juicio ejecutivo. Esto indicaría de primera mano que según las reglas procesales generales, el exequatur debería tramitarse por la vía ordinaria (artículo $59 \mathrm{CPC}$ ) porque no tiene asignado un cauce procesal específico ${ }^{12}$, lo cual también motiva otras interrogantes: si se trata entonces

11. Entre las principales: la Convención sobre Derecho Internacional Privado (Código Sánchez de Bustamante) de La Habana (1928); el Convenio de Nueva York sobre Reconocimiento y Ejecución de las Sentencias Arbitrales Extranjeras (1958); la Convención sobre Exhortos o Cartas Rogatorias de Panamá (1975); la Convención Interamericana sobre Arbitraje Comercial Internacional de Panamá (1975); la Convención Interamericana sobre Eficacia Extraterritorial de las Sentencias y Laudos Arbitrales Extranjeros de Montevideo (1979). Todas estas convenciones están incorporadas a la Codificación de Derecho Internacional publicada en el R.O.-S 153 de 25 de noviembre de 2005.

12. Sobre el tema, vid. las resoluciones de la Primera Sala de lo Civil y Mercantil de la Corte Suprema de Justicia: No. 223 de 28 de septiembre de 2004, RO.-S 537 de 4 de marzo de 2005; 227 de 13 de junio de 2001, 
de un proceso declarativo, ¿cabe deducir todos los recursos previstos para las sentencias dictadas en procesos de conocimiento?

La primera respuesta sería afirmativa: no podría impedirse tal opción al interesado porque, además, el CPC mantiene un régimen abierto para recurrir ${ }^{13}$. No es que estemos de acuerdo con este sistema, pues resulta a todas luces inconveniente: naturalmente, queda abierta la puerta para alargar el proceso de reconocimiento incluso hasta la casación (y aun acciones extraordinarias como la de protección ante la Corte Constitucional) y evitar así llegar a la ejecución, hasta donde sea posible. Por eso, como se verá, el COGP ha solucionado este posible problema al establecer que solo cabe deducir aclaración o ampliación contra la resolución que resuelve la homologación de la resolución extranjera.

Con la expedición del Código Orgánico de la Función Judicial $(\mathrm{COFJ})^{14}$ se llenó otro vacío del CPC, que no establecía la competencia para el trámite de homologación, ni tampoco para la ejecución. Así, según el artículo 143 del COFJ, el exequatur será sustanciado por la sala de la corte provincial competente en razón de la materia del domicilio de la persona contra quien se quiere hacer valer la resolución, mientras que el proceso de ejecución será conocido por el juez de primer nivel especializado en razón de la materia y del domicilio del ejecutado.

Finalmente, como se anotó, el CPC no hace mención alguna a la homologación y ejecución de laudos arbitrales extranjeros. Hasta antes de la expedición del COGP, el último inciso del artículo 42 de la Ley de Arbitraje y Mediación (LAM) decía que "Los laudos dictados dentro de un procedimiento de arbitraje internacional, tendrán los mismos efectos y serán ejecutados de la misma forma que los laudos dictados en un procedimiento de arbitraje nacional". Sobre la base de esta norma, suprimida por la disposición derogatoria decimocuarta del COGP, se ha llegado a sostener que no era necesario el exequatur para proceder con la ejecución

RO. 378 de 27 de julio de 2001; 290 de 6 de julio de 2000, publicada en la Gaceta Judicial Serie XVII, No. 3, pp. 613-615, sobre la base de las opiniones de J. LARREA Holguín, y su obra Manual de Derecho Internacional Privado. En el fallo 290-2000, la Sala dijo: "[...] para la ejecución forzosa de una sentencia extranjera, el Estado en el que se pretenda llevar a ejecución tiene la potestad, a través de sus jueces y mediante un proceso de conocimiento, de verificar su encuadre con el ordenamiento jurídico, lo que se conoce como la 'nacionalización', la 'homologación' o el 'exequátur' de la sentencia extranjera, de manera que se convierta en un elemento jurídico nacional...."

13. Artículo 321: "Siempre que la ley no deniegue expresamente un recurso, se entenderá que lo concede".

14. R.O. -S 544 de 9 de marzo de 2009. 
del laudo, o o pasar incluso a la fase de apremio; sin embargo, tales interpretaciones no son admisibles, porque aun cuando el laudo tiene efecto de sentencia ejecutoriada y de cosa juzgada, al ser expedido por un tribunal extranjero, o internacional (y sin que importe el hecho de que no sea un tribunal judicial), no tiene por qué gozar de mejor calidad que la resolución judicial extranjera ${ }^{15}$, ni gozar, automáticamente, de la calidad de título de ejecución.

Creemos importante recalcar este aspecto. Esta afirmación encuentra sustento en el hecho de que tanto el arbitraje como la jurisdicción estatal tienen por objeto la resolución de conflictos de relevancia jurídica, con autoridad de cosa juzgada, aun cuando su origen sea distinto ${ }^{16}$. Quizá - lamentablemente no se dice nada en la exposición de motivos - el hecho de que tanto las sentencias judiciales como las arbitrales son en el fondo resoluciones de carácter jurisdiccional, motivó a que el legislador derogue en el COGP el último inciso del artículo 42 de la LAM, incluyéndose a los laudos arbitrales extranjeros entre los títulos de ejecución que requieren "pasar" por el exequátur.

Resta nada más recordar que existen, en esencia, tres regímenes aplicables al exequatur ${ }^{17}$ :

1. aquel que se sujeta a la existencia de un tratado o convenio internacional, lo cual, lógicamente, facilita el reconocimiento y ejecución de la resolución extranjera;

15. Cfr. S. Andrade Ubidia, "En torno al tema del reconocimiento y ejecución de sentencias extranjeras y laudos internacionales", p. 80.

16. Creemos que la tesis mixta o del equivalente jurisdiccional sobre la naturaleza del arbitraje es la que explica, de mejor manera, las relaciones entre jurisdicción ordinaria y arbitraje. Éste, en efecto, goza de plena naturaleza contractual en su nacimiento; en su desarrollo, son las partes las que fijan las reglas, pero también existe un fuerte componente normativo estatal; en su conclusión, el proceso arbitral genera una decisión - laudo- que goza de fuerza de cosa juzgada. Esta característica no puede surgir del solo acuerdo de las partes, porque de otra forma no sería posible incoar su ejecución forzosa. Para una revisión de las tesis sobre la naturaleza jurídica del arbitraje, vid. S. BARONA VILAR y M. NOODT TAQUELA, "Arbitraje comercial internacional". En: C. EsPluges Mota y D. HARGAIN (Dir.), Derecho del comercio internacional. Mercosur - Unión Europea. Buenos Aires: REUS/B de F, 2005, p. 750. Las autoras, muy ilustrativamente, señalan que, de todas formas, “debería quedar claro que «el arbitraje es arbitraje»: una institución sui generis requerida de un tratamiento y una regulación sui generis” (ibídem).

17. Vid. J. Montero Aroca y J. Flors Matíes, Tratado de proceso de ejecución, t. I, pp. 152-153. 
2. el que se sujeta al principio de reciprocidad, que es el que verdaderamente ocasiona problemas, porque depende de la buena voluntad del país receptor conceder el exequatur aun cuando el Estado de origen no lo haga con las resoluciones que provengan de aquél;

3. el más extendido, que opera en ausencia de instrumento internacional aplicable y si no existe reciprocidad, que entrega el control de regularidad de la decisión extranjera a los tribunales nacionales.

De lo anterior, bien podría afirmarse que el actual sistema del CPC es mixto, pues la verificación de los requisitos contemplados en el artículo 414 solo procede en defecto de instrumento internacional.

\section{Naturaleza jurídica del laudo arbitral que se somete al procedimien- to de homologación y ejecución}

Como se anticipó, el CPC no incluía a los laudos arbitrales entre las disposiciones sobre reconocimiento y ejecución de sentencias extranjeras, y la LAM disponía un régimen específico - incompleto sin duda - para los laudos arbitrales internacionales en el último inciso del artículo 42. El COGP derogó esta norma (disposición derogatoria decimocuarta) y, entre los artículos 102 a 106, ha dispuesto un solo régimen de reconocimiento y ejecución para las resoluciones extranjeras; sin embargo, antes de analizarlo, resulta necesario establecer aunque sea someramente cuál es la naturaleza del laudo arbitral que se somete a reconocimiento/ejecución, para intentar explicar por qué el nuevo código procesal ha unificado las aguas, y sobre todo, para analizar, posteriormente, si sus regulaciones son o no razonables o si por el contrario, constituyen un óbice para la eficacia de los laudos internacionales.

Si la homologación de una resolución extranjera persigue que adquiera la eficacia de cosa juzgada material ${ }^{18}$, resulta lógico que adquiera fuerza ejecutiva y se pueda pasar entonces a la fase de ejecución. No es jurídicamente posible obviar este primer paso, por un principio procesal básico: no puede incoarse ejecución sin título de ejecución. Creemos que ni siquiera una lectura literal del último inciso del artículo 42 de la LAM daba para

18. De la verificación de los requisitos de regularidad viene entonces tal calidad. Vid. J. FERnánDEZ RozAS, 
esa conclusión. Cuando la norma señalaba que "Los laudos dictados dentro de un procedimiento de arbitraje internacional, tendrán los mismos efectos y serán ejecutados de la misma forma que los laudos dictados en un procedimiento de arbitraje nacional", quería decir - y así lo sostenemosque los laudos accedían a la fase de ejecución una vez que adquieran naturaleza de títulos de ejecución según el ordenamiento jurídico ecuatoriano.

Decíamos que el título de ejecución da derecho al interesado para iniciar el proceso de ejecución ${ }^{19}$. Pero, ¿de dónde nace aquella calidad? Si el título de ejecución se define como aquel "documento en el que consta la obligación de la parte contra la cual se ha de dirigir el proceso de ejecución" y por tanto, se basta a sí mismo al dar derecho a incoar la actividad ejecutiva - convirtiéndose así en un verdadero presupuesto procesal de la ejecución-, resulta conceptualmente difícil, por decir lo menos, asumir sin más tal calidad en una resolución extranjera, sea sentencia judicial o laudo.

$\mathrm{Si}$, por otra parte, no hay razón de fondo para que el laudo internacional goce de mejor calidad que la sentencia extranjera (recuérdese nuestra adhesión a la tesis del equivalente jurisdiccional), a menos de que no exista un instrumento internacional que releve de este requisito, resulta incontestable que a través del exequatur que los homologa, estas resoluciones adquirirán fuerza ejecutiva. Sin ese proceso de homologación, que reconoce su fuerza de cosa juzgada, se dejaría de lado el principio nulla exequtio sine titulo ya mencionado.

Aun en espacios donde se ha discutido con fuerza la necesidad de eliminar el exequatur (inclusive para títulos no judiciales) ${ }^{20}$, se ha advertido que las diferencias entre los ordenamientos procesales entre países hacen difícil llegar a ese objetivo. De ahí, pues, que en ausencia de una normativa internacional específica que elimine la necesidad de homologación, deba verificarse al menos si la resolución extranjera puede o no tener la calidad

y S. SÁNCHEZ LORENZO, Derecho internacional privado. 3ra. edición. Madrid: Civitas, 2004, pp. 214-232.

19. Cfr. L. Pietro-Castro y L. Ferrándiz, Tratado de derecho procesal civil. Proceso declarativo, t. II, Proceso de ejecución. 2da. Edición. Pamplona: Aranzadi, 1985, p. 686).

20. Por ejemplo, en la Unión Europea, con el Reglamento 805/2004, que busca suprimir la homologación para resoluciones judiciales, transacciones judiciales y documentos públicos con fuerza ejecutiva en materia de créditos no impugnados. Disponible en <http://eur-lex.europa.eu/legal-content/ES/TXT/?uri=URISERV:133190\#amendingact> (acceso: 15 de julio de 2015). 
en la que tanto se ha insistido, pues la ejecución, al final de cuentas, implica el uso de medidas de fuerza si el ejecutado no cumple voluntariamente con la decisión.

No es posible dejar de lado esta implicación y, aun con el recelo que pueda generar la intervención judicial - que también, hay que decirlo, suele manifestar su desconfianza hacia las decisiones que no provienen de su sede-, mientras el ordenamiento jurídico no otorgue potestad ejecutiva a los árbitros, o a los particulares, es necesario recalcar en que el exequatur otorga la calidad de título de ejecución a la resolución que inicialmente no tiene por qué gozar de esa calidad en un espacio territorial distinto a aquel en que fue expedida.

Aunque algunos han señalado que ni siquiera en instrumentos tan importantes como la Convención de Nueva York de 1958 se establece claramente el porqué de la distinción entre reconocimiento y ejecución, por lo cual debería más bien hablarse de eficacia de las resoluciones extranjeras ${ }^{21}$, aquella separación continúa hasta la presente fecha, sin que se determine concretamente si el exequatur constituye o no un óbice o simplemente un trámite innecesario. Como se verá en el siguiente acápite, las convenciones de Nueva York y de Panamá no imponen requisitos que puedan considerarse gravosos; la eficacia debe mirársela en torno, principalmente, a la actuación del juez o tribunal receptor, quien deberá estar en primer lugar a lo dispuesto por el instrumento internacional respectivo.

\section{El reconocimiento y ejecución de laudos arbitrales internacionales en las convenciones de Nueva York de 1958 y Panamá de 1975}

En este ámbito, se presentan dos elementos que dificultan la regulación del reconocimiento y ejecución de resoluciones judiciales o arbitrales extranjeras: la presencia de elementos internacionales (sean personales o materiales) en el conflicto, y el hecho de que cada país cuenta con un ordenamiento procesal distinto. Nos referimos a esta última realidad para tener presente que la

21. Cfr. V. H. GUERRA, "Reconocimiento y ejecución de laudos arbitrales”. En: V. De MAEkelt, et al. (Dir.), Derecho procesal civil internacional. Caracas: Academia de Ciencias Políticas y Sociales, 2010, pp. 568-569. 
ejecución de una resolución incumbe únicamente a los órganos judiciales del país receptor; en consecuencia, las normas sobre la materia se refieren a los requisitos aplicables a dicho trámite, y esas disposiciones necesariamente se referirán a los requisitos que un título de ejecución (categoría a la que hemos apelado para referirnos al laudo internacional) precisa para ser tal.

Los instrumentos internacionales surgen para unificar criterios y definir las prácticas que los países adoptarán en relación a una determinada institución; en suma, para facilitar la práctica en la materia de que se trate. En el caso del derecho procesal existe cierta dificultad, acaso motivada por la idea de que sus normas son de derecho público y, por tanto, indisponibles; pero las labores de unificación en esta materia han partido de la idea de que es necesario reconocer instituciones comunes a los distintos ordenamientos jurídicos ${ }^{22}$, así como las bases que facilitan enormemente la colaboración interjurisdiccional.

La labor de organismos internacionales como la Comisión de las Naciones Unidas para el Derecho Mercantil Internacional (CNUDMI o UNCITRAL por sus siglas en inglés), o de instituciones como el International Council for Commercial Arbitration (ICCA) ha sido y continúa siendo valiosa para definir esos criterios comunes y posibilitar así la adopción no solo de instrumentos internacionales, sino también guías para que los ordenamientos internos de los países se modernicen y adapten a las nuevas realidades. En el caso del reconocimiento y homologación de laudos internacionales, un valioso instrumento, la Guía del ICCA para la interpretación de la Convención de Nueva York de 195823, recuerda que los jueces de los Estados receptores se enfrentan en esta materia principalmente a dos retos:

1. la complejidad propia de los tratados internacionales;

2. lograr mantener su objetividad sin favorecer al nacional contra quien, por regla general, se pretende la ejecución del laudo internacional.

22. Prueba de ello, en el ámbito del derecho procesal, es el Anteproyecto de Código procesal civil modelo para Iberoamérica (Montevideo: Editorial M.B.A., 1988), o el Proyecto de Código modelo de cooperación interjurisdiccional para Iberoamérica, ya mencionado, preparados por el Instituto Iberoamericano de Derecho Procesal.

23. (Trad. al español de Alexander Aizenstatd), disponible en <http://www.oas.org/es/sla/ddi/docs/arbitraje_comercial_conveciones_guia_interpretacion_convencion_NY.pdf >,p. 7 . 
Si bien los mecanismos procesales para el reconocimiento y ejecución de laudos internacionales contemplados por la Convención sobre el reconocimiento y la ejecución de las sentencias arbitrales extranjeras de Nueva York de 1958 (Convención de Nueva York) dependen, en buena parte, de la confianza que se pueda depositar en la actuación de los jueces nacionales, la Guía hace notar que el principio de reciprocidad puede jugar malas pasadas a la hora en que la parte interesada requiere de la colaboración de aquellos; por otro lado, siempre hay que tomar en cuenta que, en el proceso de recepción de los instrumentos internacionales, las legislaciones internas pueden alterar los principios sentados por la convención o el tratado en cuestión. La Guía recuerda - sobre la base de los principios de interpretación sentados por la Convención de Viena sobre el Derecho de los Tratados de 1969-, que el derecho contenido en instrumentos internacionales suscritos y ratificados por los Estados nacionales forma parte de su ordenamiento jurídico interno y, por tanto, los jueces están en la obligación de aplicar dicha normativa en el sentido que más favorezca a su efectiva vigencia.

Lo anterior, que parece una verdad incontestable, resulta sin embargo puesto a dura prueba cuando se trata de hacer eficaz un laudo internacional, no solo por el factor "desconfianza" que suele presentarse internamente frente a estas resoluciones - ello sucede aun con las sentencias judiciales extranjerassino también porque muchos jueces no conocen a profundidad las disposiciones de ciertos instrumentos internacionales, y porque la legislación interna no facilita, tampoco, el proceso de nacionalización del laudo ${ }^{24}$.

La Guía señala que la finalidad de la Convención de Nueva York es "promover el comercio internacional y la resolución de conflictos internacionales a través del arbitraje", por lo cual sus disposiciones están destinadas a facilitar el reconocimiento y ejecución de laudos arbitrales internacionales; entonces, los tribunales receptores "deben de adoptar un enfoque a favor de la ejecución al interpretar la Convención", escogiendo, entre las varias interpretaciones posibles, aquella que beneficie el reconocimiento y ejecución de la decisión.

24. Un interesante resumen sobre las diversas posiciones adoptadas por las leyes arbitrales de los países latinoamericanos, puede encontrarse en F. CANTUARIAS, "Problemática general de la práctica del arbitraje internacional en Latinoamérica”. En el panel: "Arbitration Developments in Latin America”, New York State Bar Association, International Law and Practice Section, Santiago, noviembre de 2004; disponible en <http://www.law.ufl.edu/_pdf/academics/centers/cgr/7th_conference/PROBLEMATICA_GENERAL_ DE_LA_PRACTICA_DEL_ARBITRAJE_INTERNACIONAL_EN_LATINOAMERICANA.pdf $>$; acceso: 16 de julio de 2015 . 
Ello es particularmente importante para que el juzgador receptor tenga presente que las causales para el reconocimiento y ejecución de un laudo internacional deben ser interpretadas en forma restrictiva. Además, el denominado "sesgo a favor de la ejecución" impone que, si existiesen otros instrumentos internacionales aplicables al caso, los tribunales receptores deben aplicar aquel que favorezca la máxima eficacia del laudo internacional ${ }^{25}$. Añadiremos que si el régimen legal del país receptor fuese aún más favorable, debería aplicarse preferentemente.

En la Convención de Nueva York, el sesgo a favor de la ejecución se manifiesta en el principio sentado por el artículo III: "[...] Para el reconocimiento o la ejecución de las sentencias arbitrales a que se aplica la presente Convención, no se impondrán condiciones apreciablemente más rigurosas, ni honorarios o costas más elevados, que los aplicables al reconocimiento o a la ejecución de las sentencias arbitrales nacionales." Este es, en nuestro criterio, el aporte esencial de la Convención, que se desarrolla a continuación en los artículos IV y V.

La Convención de Nueva York trata insistentemente sobre el reconocimiento u homologación y sobre la ejecución. Creemos, pues, que en estos dos términos se sustenta, una vez más, el hecho de que el proceso de reconocimiento no puede ser obviado, a menos de que, como la Guía recuerda, exista un instrumento internacional más favorable o esa facilidad la incorpore la legislación procesal del país donde se pretende tenga eficacia el laudo. La frase "no se impondrán condiciones apreciablemente más rigurosas" contenida en el artículo III, no debería interpretarse como una necesidad de eliminar el exequatur como paso previo. De todas formas, la Convención señala que todo el trámite se efectuará conforme las disposiciones procesales del país receptor, con arreglo a los principios sentados por ella. Lo que ha de buscarse, entonces, es acomodar la legislación del país receptor a la Convención, es decir, no imponer condiciones adicionales en ese sistema normativo.

Las situaciones descritas en el artículo IV, que trata de la demanda que el interesado ha de presentar (nuevamente, este término nos remite a

25. Ibídem. 
un proceso previo de reconocimiento del laudo), se refieren a cuestiones de índole formal, necesarias en esencia para verificar que se haya respetado el debido proceso arbitral, que la decisión haya sido expedida por quien gozaba de jurisdicción de conformidad al convenio arbitral y que la resolución esté ejecutoriada:

a) El original debidamente autenticado de la sentencia o una copia de ese original que reúna las condiciones requeridas para su autenticidad;

b) El original del acuerdo a que se refiere el artículo II, o una copia que reúna las condiciones requeridas para su autenticidad."

2. Si esa sentencia o ese acuerdo no estuvieran en un idioma oficial del país en que se invoca la sentencia, la parte que pida el reconocimiento y la ejecución de esta última deberá presentar una traducción a ese idioma de dichos documentos. La traducción deberá ser certificada por un traductor oficial o un traductor jurado, o por un agente diplomático o consular.

El artículo V trata sobre los motivos para denegar el reconocimiento y ejecución del laudo, los cuales deben ser probados por la parte en contra de quien se insta el proceso. Esto quiere decir claramente que la carga de la prueba de la autenticidad del laudo, del cumplimiento de los requisitos atinentes al debido proceso arbitral, así como de la posibilidad de sujetar a arbitraje la materia de la controversia, recaerá, siempre, en el demandado/ejecutado. Por ello, creemos que es bastante difícil que el tribunal receptor pueda negarse a reconocer y ejecutar un laudo internacional, a menos de que existan graves violaciones al debido proceso arbitral o que la materia de la causa no haya sido materia del convenio, o no susceptible de someterse a este método alternativo de solución de controversias. Todas son cuestiones elementales y necesarias para sustentar, incluso, la legitimidad de las decisiones arbitrales internacionales.

Los motivos para negar el reconocimiento y ejecución de un laudo internacional contemplados en el artículo V señalan: 
1. Sólo se podrá denegar el reconocimiento y la ejecución de la sentencia, a instancia de la parte contra la cual es invocada, si esta parte prueba ante la autoridad competente del país en que se pide el reconocimiento y la ejecución:

a) Que las partes en el acuerdo a que se refiere el artículo II estaban sujetas a alguna incapacidad en virtud de la ley que es aplicable o que dicho acuerdo no es válido en virtud de la ley a que las partes lo han sometido, o si nada se hubiera indicado a este respecto, en virtud de la ley del país en que se haya dictado la sentencia; o

b) Que la parte contra la cual se invoca la sentencia arbitral no ha sido debidamente notificada de la designación del árbitro o del procedimiento de arbitraje o no ha podido, por cualquier otra razón, hacer valer sus medios de defensa; o

c) Que la sentencia se refiere a una diferencia no prevista en el compromiso o no comprendida en las disposiciones de la cláusula compromisoria, o contiene decisiones que exceden de los términos del compromiso o de la cláusula compromisoria; no obstante, si las disposiciones de la sentencia que se refieren a las cuestiones sometidas al arbitraje pueden separarse de las que no han sido sometidas al arbitraje, se podrá dar reconocimiento y ejecución a las primeras; 0

d) Que la constitución del tribunal arbitral o el procedimiento arbitral no se han ajustado al acuerdo celebrado entre las partes o, en defecto de tal acuerdo, que la constitución del tribunal arbitral o el procedimiento arbitral no se han ajustado a la ley del país donde se ha efectuado el arbitraje; o

e) Que la sentencia no es aún obligatoria para las partes o ha sido anulada o suspendida por una autoridad competente del país en que, o conforme a cuya ley, ha sido dictada esa sentencia.

2. También se podrá denegar el reconocimiento y la ejecución de una sentencia arbitral si la autoridad competente del país en que se pide el reconocimiento y la ejecución, comprueba: 
a) Que, según la ley de ese país, el objeto de la diferencia no es susceptible de solución por vía de arbitraje; o

b) Que el reconocimiento o la ejecución de la sentencia serían contrarios al orden público de ese país."

No es posible, por razones de espacio, realizar un análisis pormenorizado del objeto de cada uno de estos motivos. No obstante esa limitación de espacio, diremos que pueden agruparse en:

1. causas relativas a la debida constitución de la relación jurídica en el proceso arbitral (numeral 1, letras a y b);

2. causas relacionadas con vicios de incongruencia (numeral 1, letra c);

3. motivos relativos a la falta de jurisdicción y competencia del tribunal y a la materia del arbitraje (numeral 1, letra d y numeral 2, letras a y b);

4. motivos relacionados con la falta de ejecutoriedad del laudo (numeral 1, letra e). Todas, excepto la última, son cuestiones estrictamente procesales.

La Convención Interamericana de Panamá sobre arbitraje comercial internacional de 1975 (Convención de Panamá) no resulta tan completa como la de Nueva York, esencialmente porque no contiene una declaración minuciosa de los campos a los que es aplicable; no obstante, se infiere que es aplicable a laudos internacionales en materia comercial ${ }^{26}$.

Aunque de primera mano puede afirmarse que sus disposiciones no se contradicen con las de la Convención de Nueva York, hay dos temas sobre los cuales vale la pena detenerse brevemente: [1] la Convención de Panamá establece que se deberá acompañar no solo copia auténtica de la

26. Vid. A. VAN DER Berg, "The New York Convention 1958 and Panama Convention 1975: redundancy or compatibility?", En: <http://www.newyorkconvention.org/publications/full-text-publications/full-text-publications/the-new-york-convention-1958-and-panama-convention-1975-redundancy-or-compatibility>, pp. 222-223 (acceso: 20 de julio de 2015). 
sentencia o laudo, sino también del auto que demuestre que la resolución está ejecutoriada ${ }^{27}$; [2] se denegará el reconocimiento y ejecución si la parte contra quien se invoca el laudo internacional demuestra en el exequatur que en el procedimiento arbitral, no se pudo ejercer su derecho a la defensa ${ }^{28}$. Como se aprecia de su simple lectura, ninguna de las condiciones antes mencionadas comporta situaciones más gravosas que las establecidas por la Convención de Nueva York; en el último caso, la prueba de la posible vulneración del debido proceso arbitral incumbe siempre a la parte contra quien se hace valer el laudo.

Finalmente, ambas convenciones coinciden en el hecho de que los procesos de homologación y ejecución del laudo por el tribunal receptor no deben implicar, bajo ninguna circunstancia, un pronunciamiento sobre el fondo del asunto; lo contrario implicaría desatender su espíritu e imponer una traba a la eficacia de los laudos internacionales.

En el siguiente acápite se analizará si la nueva normativa ecuatoriana impone otros requisitos, y si representa o no un avance en esta materia. Se analizará con un poco más de detalle lo relativo a la contradicción que pudiera presentar el laudo internacional con el orden público nacional, para establecer si, en este particular aspecto, el COGP ha impuesto una diferenciación razonable cuando se trata de laudos internacionales expedidos contra el Estado.

\section{El Código Orgánico General de Procesos y las normas sobre homo- logación y ejecución de sentencias, laudos arbitrales y actas de me- diación expedidos en el extranjero}

En los números 1 y 2 de este artículo, analizamos que la normativa todavía vigente del CPC para la homologación y ejecución de resoluciones extranjeras es anticuada e insuficiente para regular tan importante materia; que el COFJ ha llenado el vacío relativo a la competencia para sustanciar

27. Artículo 3, letra c: "Los documentos de comprobación indispensables para solicitar el cumplimiento de las sentencias, laudos y resoluciones jurisdiccionales son los siguientes: [...] c) Copia auténtica del auto que declare que la sentencia o el laudo tiene el carácter de ejecutoriado o fuerza de cosa juzgada."

28. Artículo 5: "1. Solo se podrá denegar el reconocimiento y la ejecución de la sentencia, a solicitud de la parte contra la cual es invocada, si esta prueba ante la autoridad competente del Estado en que se pide el reconocimiento y la ejecución: [...] b.Que la parte contra la cual se invoca la sentencia arbitral no haya sido debidamente notificada de la designación del árbitro o del procedimiento de arbitraje o no haya podido, por cualquier otra razón, hacer valer sus medios de defensa”. 
el exequátur y el procedimiento de ejecución posterior, y que el COGP derogó el último inciso del artículo 42 de la LAM, para que el trámite sea regulado íntegramente en el nuevo código procesal.

Para comprender todos estos temas, es necesario iniciar por el último aspecto. El inciso final del artículo 42 decía que los laudos internacionales tendrán los mismos efectos y serán ejecutados de la misma forma que los laudos nacionales. Esta disposición debía leerse en conjunto con el artículo 32 de la LAM, que señala que los laudos tienen efecto de sentencia ejecutoriada y de cosa juzgada, por lo cual se ejecutan del mismo modo que las sentencias de última instancia.

Como se estableció, no es posible desprender sin más que el laudo internacional goza de aquellas calidades, pues sin que se discuta sobre las resoluciones que adopta, solo adquiere carta de título de ejecución una vez que se ha verificado requisitos mínimos de regularidad. Aunque es necesario que los laudos internacionales se ejecuten prontamente, el proceso de reconocimiento tiene por objeto "prevenir eventuales infracciones al orden público ecuatoriano", y tal requisito - bien se ha argumentado- va en línea con lo señalado por la Convención de Nueva York ${ }^{29}$.

El verdadero problema en la legislación todavía vigente se encuentra, como advertimos, en que la resolución resultante del exequatur, al sustanciarse en un proceso ordinario, sería susceptible de recursos ordinarios y extraordinarios y hasta acciones como la extraordinaria de protección; pero aun este severo inconveniente, creemos, no puede dar lugar a sostener que el examen de los requisitos de regularidad pueda efectuarse directamente en la fase de ejecución. Por esto, tampoco concordamos con la propuesta - formulada en relación a la legislación todavía vigente - de que el estudio sobre los requisitos de regularidad podría realizarse en el auto de mandamiento de ejecución, que forma parte de la vía de apremio ${ }^{30}$, pues cualquier actividad cognitiva o decisoria - recuérdese que el demandado.

29. Cfr. C. Coronel Jones, "Presente y futuro del arbitraje comercial en el Ecuador: Hacia una nueva ley". En: Latin Arbitration Law (<http://www.latinarbitrationlaw.com/presente-y-futuro-del-arbitraje-comercial-en-el-ecuador-hacia-una-nueva-ley>); acceso: 23 de julio de 2015.

30. Cfr. X. ANDRADE CADENA, "Reconocimiento y ejecución de laudos extranjeros en el Ecuador: un camino inexplorado". En: <http://www.andradeveloz.com/newSite/descargas/publicaciones/reconocimiento_y_ejecucion_de_laudos_extranjeros_en_el_ecuador.pdf>, p. 12 (acceso: 23 de julio de 2015). 
podría oponer una serie de argumentos contra la "nacionalización" del laudo- es ajena a esta etapa procesal, cuyo único objeto, incluido el auto antes señalado, es instrumentar la orden coercitiva del juzgador para dar vida a las disposiciones del título de ejecución.

Ya que al CPC le quedan pocos meses de vida, dejemos de lado esta preocupación y veamos, más bien, las ventajas y desventajas de la regulación contemplada por el COGP.

En el nuevo código se aprecia, en buena parte, la propuesta que formuló en su momento el Instituto Ecuatoriano de Derecho Procesal ${ }^{31}$, desde el cual se aprecia que es necesario un proceso de homologación o reconocimiento cuyo objeto es verificar requisitos de regularidad de la decisión extranjera. Frente al CPC, puede afirmarse de modo general que tanto el exequatur como la fase de ejecución configuran un modelo más acorde con los tiempos actuales, aunque el articulado final del COGP difiere bastante en algunos puntos del proyecto del Instituto, especialmente en el tratamiento desigual, diríase de verdadero privilegio, cuando se trata de laudos dictados contra el Estado.

En primer lugar, destaca el hecho de que el trámite es aplicable tanto a sentencias como a laudos. Se incluye también a las actas de mediación, lo que refuerza la idea de que el exequatur es el mecanismo procesal ideal para regularizar la resolución extranjera.

El COGP deja en claro que el exequatur no tiene por objeto revisar el fondo del asunto resuelto por el tribunal internacional o extranjero, sino únicamente verificar requisitos de regularidad (artículo 103); se señala también que la fuerza de la resolución tiene su sustento en primer lugar en los instrumentos internacionales ratificados por Ecuador; igualmente, se determina que en materia de niñez y adolescencia, se estará a lo dispuesto por el código de la materia y los instrumentos internacionales respectivos ${ }^{32}$.

31. Projusticia-Instituto Ecuatoriano de Derecho Procesal, Proyecto de Código de Procedimiento Civil, Quito, Abya Yala, 2007.

32. En esta materia se ha considerado necesario otorgar una tutela muy expeditiva. En ciertos procesos, como el contemplado en la Convención interamericana sobre obligaciones alimentarias (R.O.-S 153 de 25 de noviembre de 2005), es posible incoar directamente la ejecución "en forma sumaria" (artículo 13), incluso de resoluciones que han sido apeladas, pues la convención determina expresamente que el recurso en materia de obligaciones alimentarias no tiene efecto suspensivo. También se aplica este beneficio a autos interlocutorios y medidas provisionales expedidas en materia de alimentos (artículo 17). 
La competencia para el exequatur, como se había señalado, corresponde a la sala de la corte provincial competente en razón de la materia, del domicilio de la persona contra quien se hará valer la resolución. El tribunal deberá verificar (artículo 104):

1. Que tengan las formalidades externas necesarias para ser considerados auténticos en el Estado de origen.

2. Que la sentencia pasó en autoridad de cosa juzgada conforme con las leyes del país en donde fue dictada y la documentación anexa necesaria está debidamente legalizada.

3. Que de ser el caso, estén traducidos.

4. Que se acredite con las piezas procesales y certificaciones pertinentes que la parte demandada fue legalmente notificada y que se haya asegurado la debida defensa de las partes.

5. Que la solicitud indique el lugar de citación de la persona natural o jurídica contra quien se quiere hacer valer la resolución expedida en el extranjero.

Para efectos del reconocimiento de las sentencias y laudos arbitrales en contra del Estado, por no tratarse de asuntos comerciales, deberá además demostrarse que no contrarían las disposiciones de la Constitución y la ley, y que estén arregladas a los tratados y convenios internacionales vigentes. A falta de tratados y convenios internacionales se cumplirán si constan en el exhorto respectivo o la ley nacional del país de origen reconoce su eficacia y validez.

Como se aprecia de esta disposición, los números 1, 2, 3 y 5 no implican mayor problemática y reiteran los requisitos que también se encuentran en la Convención de Nueva York y la Convención de Panamá. Entonces, es necesario detenerse en el número $4 \mathrm{y}$ en el último inciso.

El número 4 podría inicialmente interpretarse como una carga para el requirente, quien debería probar, que se respetaron los aspectos relativos al debido proceso que se indican en el artículo. Pero dicha "carga" se supli- 
ría y se lograría, formalmente, si el requirente acompaña la copia del expediente, y de piezas procesales tales como las razones de citación/notificación, de la cláusula arbitral o del contrato que lo contiene y de la resolución en donde el tribunal ha decidido sobre su competencia y los aspectos formales de los medios probatorios presentados por las partes. No cabría, bajo ninguna circunstancia, que se realice un análisis sobre temas como la negativa del tribunal a actuar alguna prueba por impertinente o inconducente, o respecto a la motivación del tribunal.

Por otra parte, el "sesgo a favor de la ejecución" contenido en la Convención de Nueva York y que también se encuentra en la Convención de Panamá, se debería expresar en el exequatur como manifestación del principio pro actione, el cual obliga a jueces y tribunales a interpretar la norma procesal de la forma que más favorezca el derecho a la tutela efectiva $^{33}$. El artículo 103 tácitamente incorpora el principio al señalar la fuerza de la resolución tiene su sustento en primer lugar en los tratados y convenios internacionales ratificados por Ecuador. Y hacia allá debe mirarse en primer lugar, además, por un evidente principio de supremacía normativa de aquellos instrumentos internacionales.

Mención aparte merece, igualmente, el último inciso del artículo 104 del COGP. Esta disposición, que no constaba en el proyecto resultado del segundo debate en la Asamblea Nacional, y que se incorporó gracias al veto del Ejecutivo, aumenta —en forma por demás confusa- un requisito que no se verifica en el caso del reconocimiento de laudos expedidos en procesos seguidos entre particulares. Aunque el veto señala que "[...] tratándose de sentencias y laudos arbitrales en contra del Estado, es necesario aclarar que sus actos y contratos se encuentran excluidos de la materia mercantil, pues ejerce una atribución incompatible con tal materia, habida cuenta que nace de las previsiones expresas de la Constitución de la República y la Ley"34; no existe razón de fondo para argumentar que solo en estos casos debería verificarse la conformidad del laudo con las disposiciones constitucionales y legales, "por no tratarse de asuntos comerciales". ¿Acaso un laudo internacional no podría incurrir en este problema en otros casos?

33. V. Aguirre GuZMán, Tutela jurisdiccional del crédito en Ecuador. Quito: Ediciones Legales/UASB-Ecuador, 2012, p. 143.

34. PRESIDENCIA DE LA RepúbliCA (EcuAdor), Objeción parcial al proyecto de Código Orgánico General de Procesos, 
En el proyecto de la Asamblea Nacional se decía inicialmente que la resolución extranjera no debía contrariar la Constitución y la ley, evitando el siempre indefinido - diríase por desconocido- concepto de "orden público", el cual podía abrir una puerta demasiado grande, ya que, como ha explicado la doctrina nacional, "orden público" no debería identificarse con el ordenamiento jurídico interno ${ }^{35}$, justamente, para salvar este tipo de dificultades. Con todo, el término se ha conservado en los instrumentos internacionales y se ha incorporado en la ley modelo de la CNUDMI para "atender a principios fundamentales de legislación y justicia tanto en el aspecto sustantivo como en el de procedimiento. Así, ciertos casos como la corrupción, el soborno, o el fraude y otros graves análogos constituirían un motivo de anulación" 36 .

En cuanto al procedimiento para sustanciar el exequatur, el COGP (artículo 105) establece un término muy corto (cinco días) para que el requerido presente y sustente su oposición, la cual solo debería admitirse si se acompaña a la oposición la prueba respectiva: debe tenerse presente que el código ha consagrado como regla general la de no admitir pretensiones/ excepciones o defensas sin acompañar los medios probatorios destinados a sustentar cada alegación. Precisamente, esta regla da para sostener que incumbe al requerido la carga de la prueba de que la resolución extranjera no cumple con los requisitos establecidos en el artículo 104.

De la resolución que expida la sala respectiva de la Corte Provincial, no cabe sino aclaración o ampliación, con lo cual se resuelve el problema advertido de la posibilidad, en el sistema actual, de alargar el proceso de exequatur vía interposición de recursos y acciones.

remitido el 29 de abril de 2015 a la Asamblea Nacional mediante oficio No. T.6344-SGJ-15-336, p. 13.

35. Vid. X. ANDRADE CADENA, "Reconocimiento y ejecución de laudos extranjeros...”, p. 12.

36. Cfr. J. MARÍn GonzÁlez, y R. GARCía Mirón, "El concepto de orden público como causal de nulidad de un laudo tratándose de un arbitraje comercial internacional". En: Revista de Derecho (Valdivia), Valdivia, vol. 24, n. 1, julio de 2011 (disponible en <http://www.scielo.cl/scielo.php?script=sci_arttext\&pid=S0718-09502011000100006\&lng=es\&nrm=iso >; acceso: 22 de julio de 2015). Estos autores explican que en la comisión que redactó el articulado de la ley modelo de la CNUDMI, "[...] quedó entendido que [la expresión orden público] no equivalía a la posición política o a la política internacional de un Estado, sino que abarcaba los conceptos y principios fundamentales de justicia. Se señaló que en algunos ordenamientos de tradición anglosajona ese término podría ser interpretado en el sentido de no incluir los principios de justicia procesal. Sin embargo, la Comisión estuvo de acuerdo en que debía conservarse ese apartado, ya que todos los sistemas de tradición de "derecho civi" están inspirados en el concepto francés de 'ordre public', en el que se consideran contenidos de los principios de justicia procesal; igualmente que su inserción en muchos tratados abarca los principios de legislación y justicia....”. 
Una vez ejecutoriada la sentencia homologatoria, se procederá a ejecutar la resolución, en la misma forma que las decisiones nacionales. La ejecución corresponde al juez del lugar del domicilio del requerido, competente en razón de la materia.

La disposición del artículo 106 del COGP merece una mención aparte. Esta norma señala que si se pretende introducir como medio probatorio una sentencia, laudo arbitral o acta de mediación expedidos en el extranjero, deberá seguirse previamente el proceso de homologación. La razón es simple: si se otorgase esta competencia directamente al juez del respectivo proceso con el argumento de que el documento incorpora únicamente un medio de prueba, este camino podría ser utilizado para evitar la tramitación del exequatur y alegar que la resolución extranjera fue homologada.

La fase de ejecución en el COGP está regulada en forma más adecuada que en el CPC; analizar cada una de sus disposiciones implicaría otro artículo. Diremos nada más que el principio pro actione vuelve a hacerse presente en aquella fase, cuando el COGP establece, de modo general, que incumbe al juez verificar que las disposiciones del título de ejecución se hagan realidad, para lo cual deberá dictar las disposiciones que sean necesarias a tales efectos $^{37}$.

\section{Conclusiones}

$\mathrm{Al}$ reconocimiento y homologación de laudos internacionales le falta un largo camino por recorrer en Ecuador. Las nuevas condiciones normativas establecen una serie de requisitos que, como se ha podido comprobar, están en su mayoría alineadas con lo dispuesto por la Convención de Nueva York y la Convención de Panamá, y resultan mucho más completas que las del CPC, que está a punto de fenecer. Sin embargo, se establece una excepción inaceptable respecto a los laudos internacionales dictados en contra del Estado, lo cual sin duda atentará contra la eficacia de dichas resoluciones.

37. Artículo 364: "Facultades de la o del juzgador y de las partes. La ejecución se circunscribirá a la realización o aplicación concreta de lo establecido en el título de ejecución. Las partes actuarán en plano de igualdad, pero se limitarán exclusivamente al control del cumplimiento del título de ejecución, conforme con la ley." Artículo 365.- Acceso a información de datos del ejecutado. La o el juzgador tendrá la facultad de acceder de oficio o a petición de parte, a los registros públicos de datos de la o del ejecutado, para recabar información relacionada con sus bienes. Además, brindará a la o el ejecutante todo el apoyo y facilidades para la realización de los actos necesarios dentro de la ejecución. 
Para la homologación de laudos internacionales y su posterior ejecución, la sala respectiva de la corte provincial y el juzgado de primera instancia, respectivamente, deberán verificar en primer lugar lo que establece el instrumento internacional respectivo e interpretar en todo caso las disposiciones del COGP en armonía con sesgo a favor de la ejecución contemplado en el artículo 103.

Este sesgo además deberá ser interpretado por los tribunales nacionales en la tramitación del exequatur de manera que se refuerce la eficacia del laudo internacional. Las causales que se pueden invocar en contra de su homologación deben ser probadas no por requirente, sino por el requerido, porque en el exequatur no pueden discutirse asuntos de fondo que ya fueron resueltos en el laudo. La razón es obvia: la carga de la prueba debe recaer en la parte a quien beneficiaría la alegación de que el laudo no es eficaz porque solo a ella le beneficia.

Estaríamos, por otra parte, ante un escenario de contradicción bastante restringido, cuyo objeto, en todo caso, sería verificar únicamente requisitos relacionados a la observancia del debido proceso arbitral, la congruencia del laudo o la competencia del tribunal arbitral, sin que ninguna de estas tres condiciones obligue a probar nada adicional a quien requiere ejecutar, finalmente, el laudo, ya que éste viene revestido de una presunción de validez.

Cualquier interpretación contraria vulneraría el principio pro actione y por consiguiente el artículo 75 de la Constitución de la República que consagra el derecho a la tutela efectiva, que también rige para el reconocimiento y ejecución de laudos internacionales. 